\title{
Optical Coherence Tomography in an Infant with Walker-Warburg Syndrome
}

\author{
Natsuko Mano ${ }^{a}$ Tatsuma Mitsutsuji ${ }^{a}$ Yamato Yoshikawa ${ }^{a}$ \\ Makiko Miyamoto $^{a}$ Hiroko Watanabe $^{a}$ Kazuhiro Shimizu ${ }^{a}$ \\ Michiko Miki ${ }^{\mathrm{b}} \quad$ Masashi Mimura $^{\mathrm{b}}$ Mari Ueki $^{\mathrm{b}}$ Tsunehiko Ikeda ${ }^{\mathrm{b}}$ \\ ${ }^{a}$ Department of Ophthalmology, Takatsuki Hospital, and ${ }^{b}$ Department of Ophthalmology, \\ Osaka Medical College, Takatsuki City, Japan
}

\section{Key Words}

Walker-Warburg syndrome - Optical coherence tomography · Persistent hyaloid artery . Congenital glaucoma $\cdot$ Retinal dysplasia

\begin{abstract}
Purpose: Walker-Warburg syndrome (WWS) is a type of congenital muscular dystrophy (CMD) characterised by severe brain malformation, lissencephaly, and congenital eye abnormalities. Despite the coexistence of various eye abnormalities, results from optical coherence tomography (OCT) in WWS have not previously been reported. We herein report specific OCT findings in an infant with WWS. Patients and Methods: The patient was a 14-day-old boy delivered by caesarean section at 38 weeks and 4 days of gestation and with a birth weight of 2,543 g. A cranial MRI showed lissencephaly, hydrocephalus, an encephalocele, and cerebellar hypoplasia, consistent with the diagnosis of WWS. Results: A bilateral ocular examination showed no abnormalities of the anterior eye segment. A fundus examination showed a persistent hyaloid artery in the vitreous cavity, a widespread loss of fundus pigmentation, transparent choroidal vessels (some choroidal vessel sections were visible), and the absence of a distinct macular reflex. OCT showed no foveal pit and an indistinct laminar structure of the retina. The infant subsequently developed congenital glaucoma and he then died of respiratory failure at the age of 8 months. Conclusions: WWS is associated with a high incidence of congenital eye abnormalities, and this infant showed findings consistent with WWS. OCT revealed a marked retinal dysplasia.


Mano et al.: Optical Coherence Tomography in an Infant with Walker-Warburg Syndrome

\section{Introduction}

Walker-Warburg syndrome (WWS) is a type of congenital muscular dystrophy (CMD) characterised by severe brain malformation, lissencephaly, and congenital eye abnormalities [1]. CMD is a general term for muscular dystrophies that develop at, or within a few months after birth, with symptoms of muscle weakness and muscle hypotonia. WWS is a very rare disease. Fukuyama-type CMD (FCMD), which accounts for most cases of CMD in Japan, and muscle-eye-brain syndrome, which is seen in Finland, are similar disorders showing muscle, brain, and eye abnormalities [2].

The life expectancy is usually less than 1 year in WWS, but about 20 years in FCMD, making a differential diagnosis important [2]. Eye abnormalities associated with WWS include cataract, corneal opacity, glaucoma, and retinal malformation [1]. WWS can be distinguished from FCMD by genetic testing, but the severity of eye abnormalities also differs among these pathologies; this can be useful in the diagnosis. We herein report specific findings seen on optical coherence tomography (OCT) in an infant with WWS.

\section{Case Report}

\section{History of Present Illness}

Our patient was a 14-day-old infant boy. Foetal ventriculomegaly was diagnosed at 32 weeks of gestation, and the mother was referred to the Department of Obstetrics and Gynecology at Takatsuki General Hospital in early March 2014. A foetal MRI showed lissencephaly, hydrocephalus, an encephalocele as well as cerebellar hypoplasia - WWS was suspected. The infant was delivered by caesarean section at 38 weeks and 4 days of gestation, with a birth weight of 2,543 g and an Apgar score of 5 at $1 \mathrm{~min}$ and 7 at $5 \mathrm{~min}$. A muscle hypotonia was noted at birth, and his serum creatine kinase level was high, at 12,530 IU/l, strongly suggesting a CMD. At 2 days old, the encephalocele was repaired and a ventriculoperitoneal shunt was placed for the hydrocephalus (fig. 1). The respiratory status stabilised, and the neonate was referred to our department for an ophthalmological evaluation at the age of 14 days.

\section{Findings on Initial Evaluation}

The intraocular pressure (IOP) was within normal limits: right eye $10.6 \mathrm{~mm} \mathrm{Hg}$; left eye $16.8 \mathrm{~mm} \mathrm{Hg}$ (I-care ${ }^{\circledR}$ tonometer; Revenio Group Corporation, Helsinki, Finland). The corneas were transparent bilaterally, and no cataracts were present, but a persistent hyaloid artery was seen posterior to the lens. A funduscopy showed a widespread loss of fundus pigmentation, transparent choroidal vessels (some choroidal vessel sections were visible), and the absence of a distinct macular reflex (fig. 2). OCT (iVue ${ }^{\circledR}$ portable OCT; Optovue Inc., Fremont, Calif., USA) showed no foveal pit, some laminar structure of the outer retinal layer, and an indistinct laminar structure of the inner retinal layer (fig. 3).

Genetic testing after birth showed a mutation in POMT1, a gene encoding glycosyltransferase, thus confirming the diagnosis of WWS. The infant was discharged from our hospital at 1 month old and scheduled for a follow-up evaluation with a nearby ophthalmologist. However, he was not examined for 5 months, and a re-evaluation at 5 months old showed corneal opacities and buphthalmos, a corneal diameter of $14 \mathrm{~mm}$ in both eyes, and bilateral elevated IOP (right eye, $37.6 \mathrm{~mm} \mathrm{Hg}$; left eye, $33.1 \mathrm{~mm} \mathrm{Hg}$ ) by I-care ${ }^{\circledR}$ tonometry. The infant was therefore referred to the Department of Ophthalmology at Osaka Medical College. 
Mano et al.: Optical Coherence Tomography in an Infant with Walker-Warburg Syndrome

A topical eye treatment was prescribed, but IOP remained in the high 30s. The corneal thickness was $516 \mu \mathrm{m}$ in the right eye but thinner $(389 \mu \mathrm{m})$ in the left eye. No improvement in visual function was expected, but for facial cosmetic reasons and to prevent secondary corneal injuries such as corneal perforation, cyclocoagulation was considered. However, the infant died at 8 months of age due to respiratory failure.

\section{Discussion}

WWS is a very severe type of CMD with an autosomal-recessive inheritance and a life expectancy of only 6-12 months [1]. The cause is reported to be gene mutations in POMT1 or POMT2, which encode glycoprotein enzymes $[3,4]$, but in many cases it remains unclear. The diagnostic criteria for WWS include type II lissencephaly, cerebellar malformations, retinal abnormalities, and CMD. The eye abnormalities include a high incidence of retinal lesions such as retinal dysplasia and retinal detachment $[5,6]$. Corneal opacities, shallow anterior chamber, cataracts, glaucoma, microphthalmia, and persistent hyperplastic primary vitreous have also been reported as complications [7-10].

WWS, together with FCMD and muscle-eye-brain syndrome, are 'alphadystroglycanopathies' with abnormal sugar chain moieties of alpha-dystroglycan, a component of the dystrophin-glycoprotein complex in the sarcolemma. This leads to abnormalities in the skeletal muscle, brain, myocardium, and retina, where alpha-dystroglycan is distributed [11]. Differential diagnosis between WWS and severe FCMD is particularly important in terms of predicting life expectancy.

FCMD is primarily seen in Japan, with most cases involving abnormal gene sequences inherited from common ancestors, and genetic testing shows a mutation consisting of an approximately 3 -kb retrotransposon insertion in the $3^{\prime}$ non-coding region of the fukutin gene [12]. Ocular findings in FCMD include myopia, entropion, esotropia, nystagmus, cataracts, chorioretinal lesions (retinal lattice degeneration, chorioretinal atrophy, retinal detachment), and optic disc hypoplasia [13]. The incidence of these findings increases with age. Differences in the severity of eye abnormalities between FCMD and WWS have been reported, but the details remain unclear.

Alpha-dystroglycan is involved in the central nervous system development, including adhesion with neuron basement membranes, fusion of the cerebral cortex, and angioarchitecture at the brain surface. Alpha-dystroglycan deficiency plays a central role in brain functional and structural abnormalities such as lissencephaly [11]. In the type II lissencephaly seen in WWS, histological findings include an almost complete lack of cortical differentiation (so-called laminar structure), a paucity of neurons, and abundant glial/mesenchymal tissue [14].

Our search of the literature found no previous reports of OCT used to evaluate the retina in WWS. According to previous reports using OCT, it has been discovered that as with adults, the formation of the foveal depression already exists at the neonatal stage, and that there is a clear formation of the layer structure of the retina [15-17]. OCT in our patient showed some laminar structure of the outer layer of the retina, but the laminar structure of the inner layer was indistinct. Moreover, we also observed the reflection of the innermost layer as being prominent. The internal limiting membrane is the basal lamina of the Müller cell, and there is a possibility of some type of causal relationship between retinal dysplasia as well as Müller cell dysplasia in particular, and the thickening of the internal limiting membrane. The laminar structure of the outer layer of the retina usually seen on imaging is presumed to be the external limiting membrane. The external limiting membrane is a site of Müller cell adhe- 
Mano et al.: Optical Coherence Tomography in an Infant with Walker-Warburg Syndrome

sion, and these Müller cells differentiate to some degree. However, as in the central nervous system, neurons remain undifferentiated with alpha-dystroglycan deficiency, so the laminar structure of the retina does not develop.

In an autopsy case of WWS, Gerding et al. [7] found undifferentiated neurons in the inner layer of the retina and differences between the inner and outer layers of the retina. OCT findings in our patient are consistent in terms of retinal structure. Although we could not find any literature investigating the Müller cell with autopsy cases for WWS in the scope of our investigation, it has been reported that in FCMD, which is a similar condition, there were abnormalities with the type IV collagen and laminin produced by Müller cells and that Müller cells are involved in retinal dysplasia [18]. In addition, that study reported that as with WWS, retinal dysplasia also exists with FCMD and that there is an increase in S-100 protein and glial fibrillary acidic protein in perivascular glial cells.

WWS is associated with a high incidence of congenital eye abnormalities (particularly retinal dysplasia), and OCT results in our patient were consistent with these findings. The cause of retinal dysplasia is presumed to be undifferentiated neurons due to alphadystroglycan deficiency. OCT showed an indistinct laminar structure of the retina, suggesting undifferentiated neurons. Congenital eye abnormalities may offer a clue to the diagnosis of WWS. Further case studies from an ophthalmological perspective are necessary.

\section{Acknowledgements}

The authors wish to thank John Bush for editing the paper.

\section{Statement of Ethics}

The authors have no ethical conflicts to disclose.

\section{Disclosure Statement}

The authors have no conflicts of interest to report.

\section{References}

1 Rhodes RE, Hatten HP Jr, Ellington KS: Walker-Warburg syndrome. AJNR Am J Neuroradiol 1992;13:123126.

2 Kato T, Funahashi M, Matsui A, Takashima S, Suzuki Y: MRI of disseminated developmental dysmyelination in Fukuyama type of CMD. Pediatr Neurol 2000;23:385-388.

3 Akasaka-Manya K, Manya H, Endo T: Mutations of the POMT1 gene found in patients with Walker-Warburg syndrome lead to a defect of protein 0-mannosylation. Biochem Biophys Res Commun 2004;325:75-79.

-4 van Reeuwijk J, Janssen M, van den Elzen C, Beltran-Valero de Bernabé D, Sabatelli P, Merlini L, Boon M, Scheffer H, Brockington M, Muntoni F, Huynen MA, Verrips A, Walsh CA, Barth PG, Brunner HG, van Bokhoven H: POMT2 mutations cause alpha-dystroglycan hypoglycosylation and Walker-Warburg syndrome. J Med Genet 2005;42:907-912.

-5 Shen 0, Zuckerman S, Cohen P, Rabinowitz R: Prenatal sonographic diagnosis of retinal nonattachment. J Ultrasound Med 2014;33:1095-1097.

-6 Berrocal AM, Scott IU, Flynn HW Jr: Walker-Warburg syndrome: congenital neurodysplasia and bilateral retinal folds. Ophthalmic Surg Lasers Imaging 2004;35:256-258.

-7 Gerding H, Gullotta F, Kuchelmeister K, Busse H: Ocular findings in Walker-Warburg syndrome. Childs Nerv Syst 1993;9:418-420. 
Mano et al.: Optical Coherence Tomography in an Infant with Walker-Warburg Syndrome

8 Brasseur-Daudruy M, Vivier PH, Ickowicz V, Eurin D, Verspyck E: Walker-Warburg syndrome diagnosed by findings of typical ocular abnormalities on prenatal ultrasound. Pediatr Radiol 2012;42:488-490.

-9 Agrawal P, Patel C, Abidi N, Ramchandani S, Vadhel L, Loomba A: Walker-Warburg syndrome associated with microphthalmos and megalophthalmos: a rare combination. Oman J Ophthalmol 2013;6:134-135.

10 Rehany U, Segal ZI, Rumelt S: Congenital unilateral buphthalmos in Walker-Warburg syndrome: a clinicopathological study. Eye 1999;13:778-780.

$\checkmark 11$ Toda T, Kobayashi K, Takeda S, Sasaki J, Kurahashi H, Kano H, Tachikawa M, Wang F, Nagai Y, Taniguchi K, Taniguchi M, Sunada Y, Terashima T, Endo T, Matsumura K: Fukuyama-type congenital muscular dystrophy (FCMD) and alpha-dystroglycanopathy. Congenit Anom (Kyoto) 2003;43:97-104.

$\checkmark 12$ Kondo-Iida E, Kobayashi K, Watanabe M, Sasaki J, Kumagai T, Koide H, Saito K, Osawa M, Nakamura Y, Toda T: Novel mutations and genotype-phenotype relationships in 107 families with Fukuyama-type congenital muscular dystrophy (FCMD). Hum Mol Genet 1999;8:2303-2309.

13 Tsutsumi A, Uchida Y, Osawa M, Fukuyama Y: Ocular findings in Fukuyama type congenital muscular dystrophy. Brain Dev 1989;11:413-419.

14 Bornemann A, Aigner T, Kirchner T: Spatial and temporal development of the gliovascular tissue in type II lissencephaly. Acta Neuropathol 1997;93:173-177.

15 Maldonado RS, Izatt JA, Sarin N, Wallace DK, Freedman S, Cotten CM, Toth CA: Optimizing hand-held spectral domain optical coherence tomography imaging for neonates, infants, and children. Invest Ophthalmol Vis Sci 2010;51:2678-2685.

16 Ecsedy M, Szamosi A, Karkó C, Zubovics L, Varsányi B, Németh J, Récsán Z: A comparison of macular structure imaged by optical coherence tomography in preterm and full-term children. Invest Ophthalmol Vis Sci 2007;48:5207-5211.

-17 Cabrera MT, Maldonado RS, Toth CA, O’Connell RV, Chen BB, Chiu SJ, Farsiu S, Wallace DK, Stinnett SS, Panayotti GM, Swamy GK, Freedman SF: Subfoveal fluid in healthy full-term newborns observed by handheld spectral-domain optical coherence tomography. Am J Ophthalmol 2012;153:167-175.

18 Hino N, Kobayashi M, Shibata N, Yamamoto T, Saito K, Osawa M: Clinicopathological study on eyes from cases of Fukuyama type congenital muscular dystrophy. Brain Dev 2001;23:97-107.
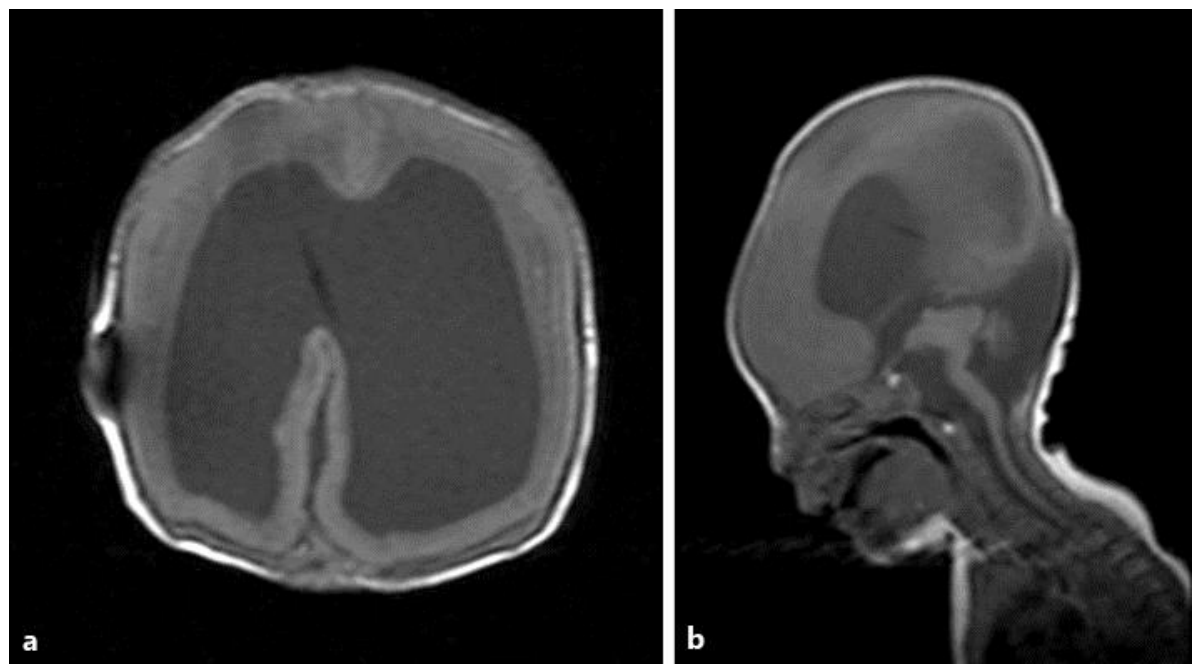

Fig. 1. Cranial MRI (T1WI) of the patient in this study at 22 days of age. a Agyria. b Lissencephaly of the brain surface, hydrocephalus, cerebellar and brainstem hypoplasia, and an enlargement of the fourth ventricle are evident. Each lesion is indicated by an arrow. (1) Agyria and lissencephaly of the brain surface, (2) hydrocephalus, (3) cerebellar hypoplasia, (4) enlargement of the fourth ventricle, and (5) brainstem hypoplasia. 
Case Reports in

Ophthalmology

\begin{tabular}{l|l}
\hline \multicolumn{2}{l|}{ Case Rep Ophthalmol 2015;6:210-215 } \\
\hline DOI: $10.1159 / 000435771$ & $\begin{array}{l}\text { C } 2015 \text { S. Karger AG, Basel } \\
\text { www.karger.com/cop }\end{array}$ \\
\hline
\end{tabular}

Mano et al.: Optical Coherence Tomography in an Infant with Walker-Warburg Syndrome

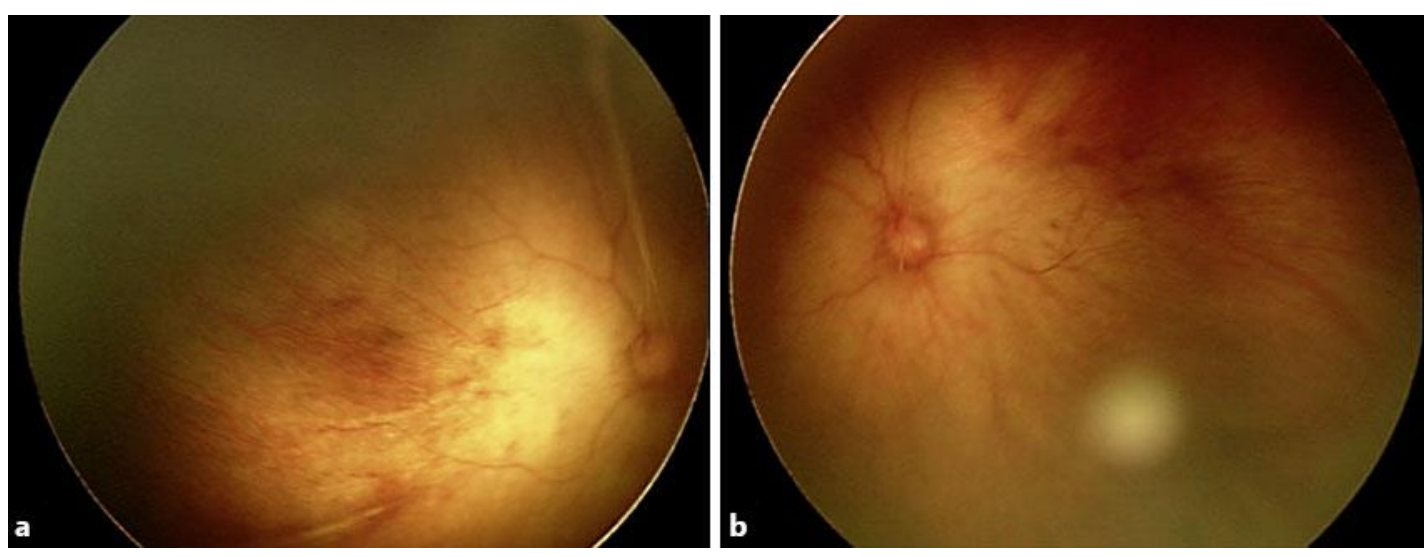

Fig. 2. Funduscopic images of the right (a) and left (b) eye show a widespread loss of fundus pigmentation, transparent choroidal vessels, and no distinct macular reflex.

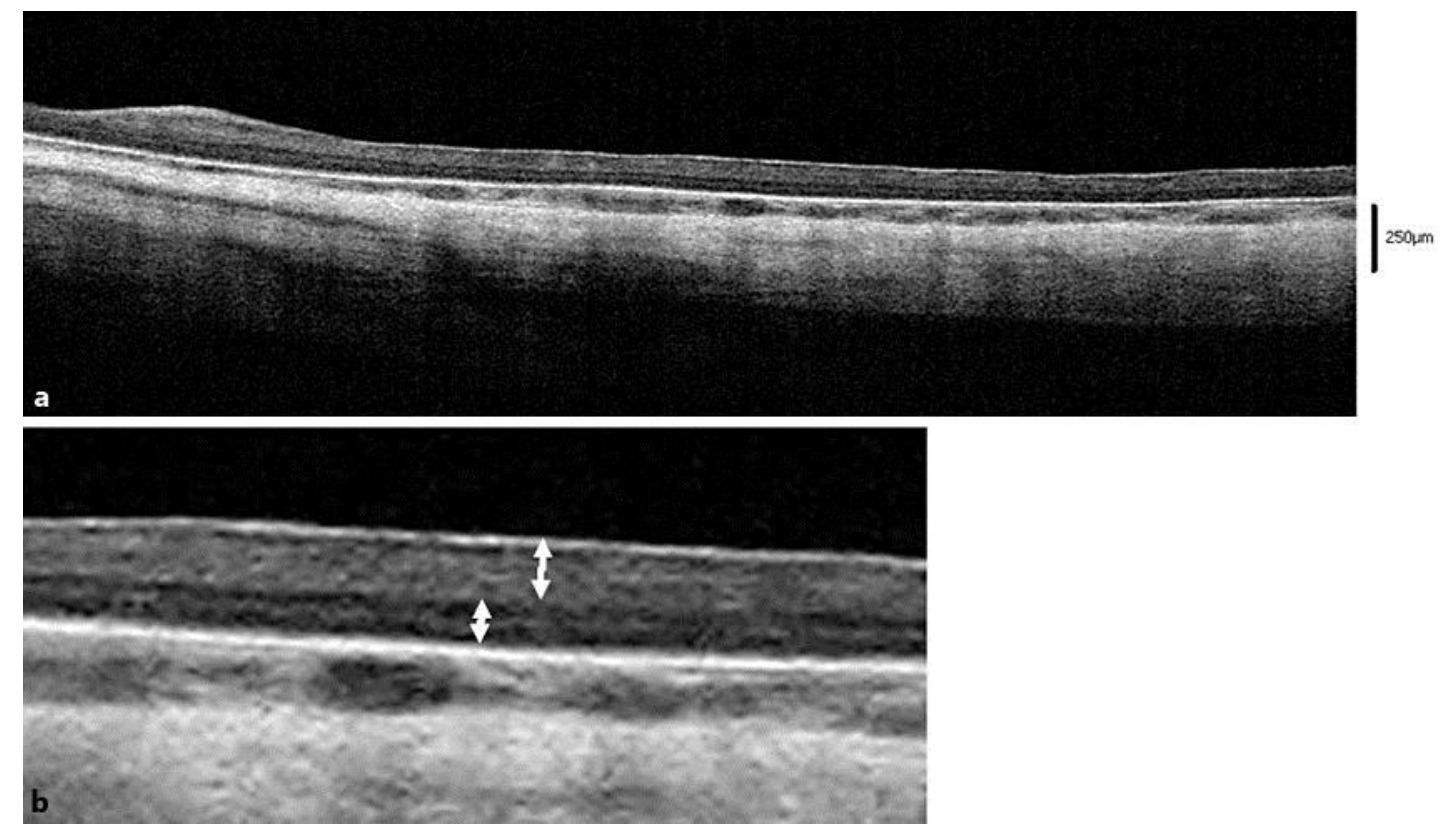

Fig. 3. OCT findings of the patient's right eye. a OCT shows no foveal pit and some laminar structure of the outer retinal layer. $\mathbf{b}$ An indistinct laminar structure of the inner retinal layer. 